\title{
Superior Helical Rim Reconstruction with a Retroauricular Perforator Transposition Flap: The Importance of a "Lifeboat" Vascular Supply
}

\author{
Federico Tamborini ${ }^{1}$ Tommaso Baroni ${ }^{2}$ Leonardo Garutti ${ }^{2}$ Elisa Bascialla ${ }^{2}$ Luigi Valdatta ${ }^{1,2}$ \\ Mario Cherubino ${ }^{1,2}$
}

1Plastic and Reconstructive Surgery, Microsurgery and Hand Surgery Unit, ASST Settelaghi, Ospedale di Circolo, Varese, Italy

${ }^{2}$ Division of Plastic and Reconstructive Surgery, Department of Biotechnology and Life Sciences, University of Insubria, Varese, Italy

Indian J Plast Surg 2021;54:240-241.

Ears are included among the most exposed regions of the head and neck to ultraviolet radiations. Basal cell carcinomas (BCCs) are about four times more common than squamous cell carcinomas (SCCs). ${ }^{1}$ Tumor excision of the superior helical rim can lead to extensive defects, amenable to reconstructive attempts, due to several aesthetic and functional concerns. Different reconstructive methods can be employed, considering the location, the dimension, and the depth of the defect itself. ${ }^{2,3}$ Primary closure after wedge resection, full-thickness skin grafts, Antia-Buch helical chondrocutaneous advancement flaps, and multistage tubed flaps are just some of the reconstructive options that have been widely described in literature. Several anatomical studies described the vascular supply of the external ear, in order to elucidate the different vascular patterns on which multiple local and perforator flaps pedicles are based. ${ }^{4,5}$ Different perforators originating from the posterior auricular artery (PAA) and the superficial auricular artery (SAA) create vascular interconnections in the superior, middle and inferior auricular regions. Therefore, the vascular supply of the retroauricular region is ensured by multiple artery perforators. ${ }^{6}$ The low donor site morbidity and the good matching in color and texture ensure that the retroauricular skin can be considered as a flap bank for ear reconstruction. ${ }^{7}$

We report a case of a 79-year-old female patient with a morpheaform BCC of the right superior helical rim. The patient was admitted to a Day-Surgery recovery, and a tumor resection under local anesthesia was performed. The resulting full-thickness defect measured $2 \mathrm{~cm} \times 1.1 \mathrm{~cm}$ ( - Fig. 1). Considering patient's multiple comorbidities and her advanced age, a single-staged flap repair was preferred. A retroauricular transposition flap was designed, estimating an exceeding length in order to ensure adequate coverage of

published online June 15, 2021
Dol https://doi.org/

$10.1055 / \mathrm{s}-0041-1726154$ ISSN 0970-0358.
Address for correspondence Federico Tamborini, MD, FEBSH, Plastic and Reconstructive Surgery, Microsurgery and Hand Surgery Unit, ASST Settelaghi - Ospedale di Circolo - Viale Borri 57, Varese, 21100 (VA), Italy (e-mail: tamborini.federico@gmail.com).

the defect as a whole (width to length ratio of 1:5) ( - Fig. 2). The vascular supply provided by the superior arterial network was considered inadequate to guarantee the survival of the entire flap. Therefore, a meticulous dissection was performed under loupe magnification, keeping above the superficial mastoid fascia. A superior retroauricular perforator was encountered, with an external diameter of $0.9 \mathrm{~mm}$ and a length of $14 \mathrm{~mm}$ (-Fig. 3). The intervening skin

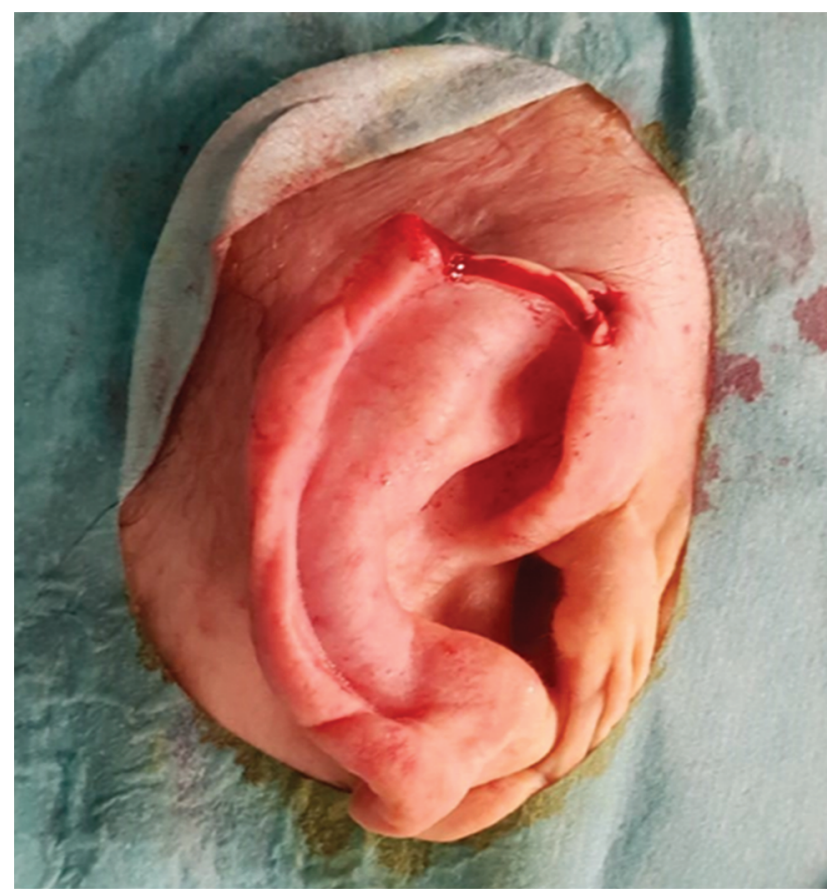

Fig. 1 Full-thickness defect involving the right superior helical rim.

(c) 2021. Association of Plastic Surgeons of India.

This is an open access article published by Thieme under the terms of the Creative Commons Attribution-NonDerivative-NonCommercial-License, permitting copying and reproduction so long as the original work is given appropriate credit. Contents may not be used for commercial purposes, or adapted, remixed, transformed or built upon. (https://creativecommons.org/licenses/by-nc-nd/4.0/).

Thieme Medical and Scientific Publishers Pvt. Ltd. A-12, 2nd Floor, Sector 2, Noida-201301 UP, India 


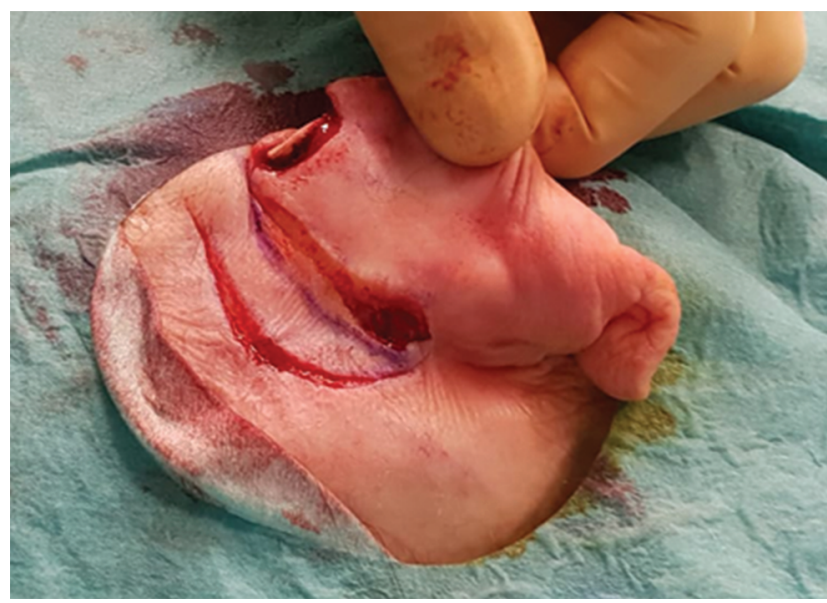

Fig. 2 A retroauricular transposition flap with a width to length ratio of $1: 5$ was designed.

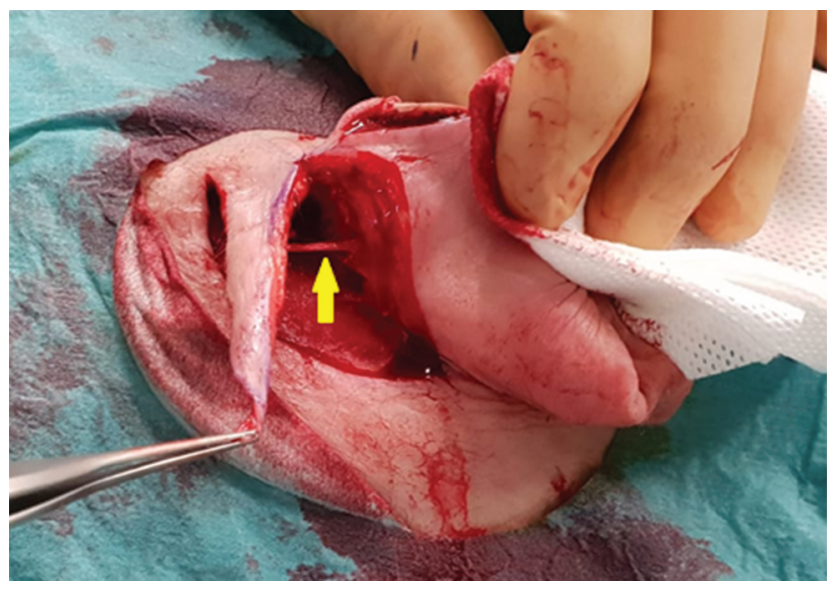

Fig. 3 A superior retroauricular perforator was dissected, with an external diameter of $0.9 \mathrm{~mm}$ and a length of $14 \mathrm{~mm}$.

between the defect and the proximal portion of the helix was removed, in order to avoid the necessity of performing a pedicle detachment at a second stage. The entirely dissected flap was transposed and sutured into the defect with a Nylon $4-0$. Donor site was easily closed by primary intention after accurate hemostasis. In the early postoperative period, a mild venous congestion was observed. After 8 months of follow-up, neither flap necrosis nor tumor recurrence, scar contracture, or bulky appearance occurred. The patient was satisfied with the functional and aesthetic results achieved ( - Fig. 4 ).

The retroauricular perforator transposition flap is a simple and single-stage reconstructive method that uses retroauricular skin with little or no color mismatch. Although a meticulous dissection is needed, a good helical rim contour can be obtained even without the use of cartilage grafts.

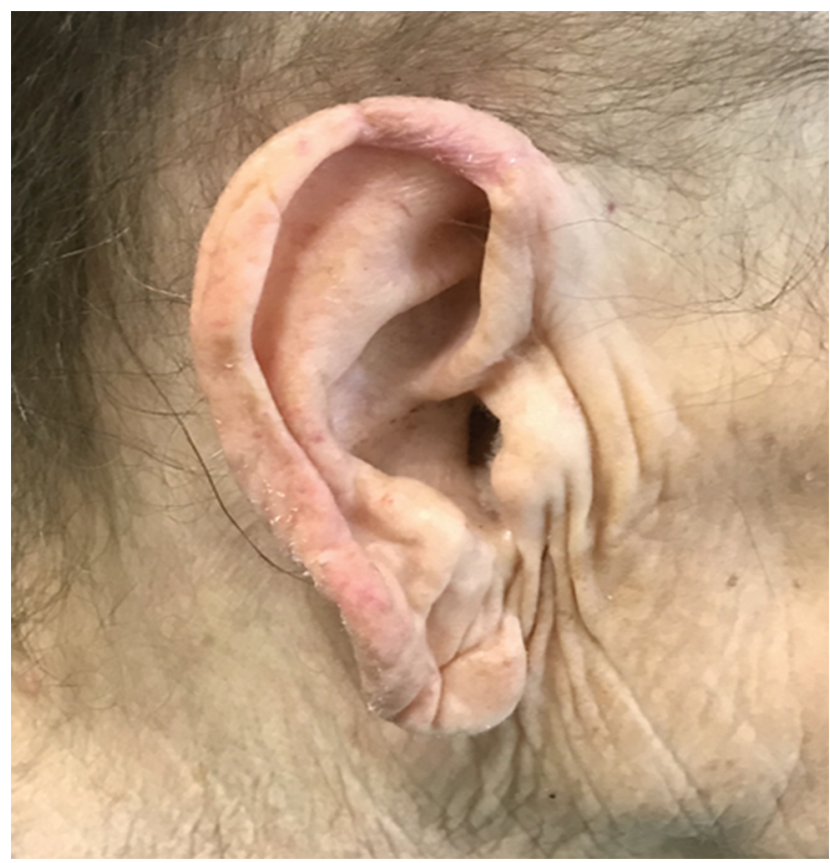

Fig. 4 Good skin color, contour and tissue elasticity were obtained. The patient was satisfied with the functional and aesthetic results achieved.

\section{Conflicts of Interest \\ None declared.}

\section{Acknowledgements}

All the authors declare that no financial support was received for this article.

\section{References}

1 Devaney KO, Boschman CR, Willard SC, Ferlito A, Rinaldo A. Tumours of the external ear and temporal bone. Lancet Oncol 2005;6(6):411-420

2 Fortier-Riberdy G, Gloster HM Jr. Reconstruction of the superior helical rim with a postauricular transposition flap. Dermatol Surg 2005;31(1):99-101

3 Daniali L, Payne E, Trovato MJ. Management and reconstruction of a helical rim defect with exposed cartilage. Eplasty 2013;13ic43. Print 2013

4 Pinar YA, Ikiz ZA, Bilge O. Arterial anatomy of the auricle: its importance for reconstructive surgery. Surg Radiol Anat 2003;25(3-4):175-179

5 Hénoux M, Espitalier F, Hamel A, Dréno B, Michel G, Malard O. Vascular supply of the auricle: anatomical study and applications to external ear reconstruction. Dermatol Surg 2017;43(1):87-97

6 Song R, Song Y, Qi K, Jiang H, Pan F. The superior auricular artery and retroauricular arterial island flaps. Plast Reconstr Surg 1996;98(4):657-667, discussion 668-670

7 Cordova A, D'Arpa S, Pirrello R, Giambona C, Moschella F. Retroauricular skin: a flaps bank for ear reconstruction. J Plast Reconstr Aesthet Surg 2008;61(Suppl 1) :S44-S51 